\title{
SEM-based Quantitative Analysis of Lunar Meteorite Northwest Africa 2727
}

\author{
Stephen M. Seddio ${ }^{1}$ and Sarah N. Valencia ${ }^{2,3}$ \\ 1. Thermo Fisher Scientific, Fitchburg, WI, USA. \\ 2. University of Maryland, Department of Astronomy, College Park, MD, USA. \\ 3. NASA Goddard Space Flight Center, Planetary Geology, Geophysics, and Geochemistry Laboratory, \\ Greenbelt, MD, USA.
}

The electron microprobe has long been the stalwart tool of mineralogical and petrographic investigation using WDS (wavelength-dispersive spectroscopy), electron imaging, and EDS (energy-dispersive spectroscopy). EPMA (electron-probe microanalysis) is a particularly useful analytical technique for the study of planetary materials given its broad analytical range (i.e., $\mathrm{B}-\mathrm{Pu}$ ) and non-destructive nature. Scanning electron microscopes (SEM) are much more common, owing to their relatively low cost, but are typically associated only with imaging and perhaps some microanalysis using EDS which may lack some of the analytical rigor typically associated with WDS. However, modern SEM-based X-ray microanalysis systems are able to achieve EPMA-like analysis using standards-based EDS. Additionally, modern X-ray microanalysis systems enable WDS analysis to be done on the SEM. Here, we compare quantitative WDS analyses of pigeonite, ferroaugite, and pyroxferroite in lunar meteorite NWA (Northwest Africa) 2727 acquired using an electron microprobe and an SEM.

A thin section of NWA 2727 was analyzed by EPMA using the 5-spectrometer JEOL JXA-8200 Superprobe at Washington University in St. Louis, USA. A $15 \mathrm{kV}$ accelerating voltage was used. The beam current was set to $25 \mathrm{nA}$ and measured at the beginning of each acquisition with an in-column Faraday cup. $\mathrm{Na}, \mathrm{Mg}, \mathrm{Al}$, and $\mathrm{Si}$ were analyzed using a TAP diffractor. Ca was analyzed using a PET diffractor. $\mathrm{Ti}, \mathrm{Cr}, \mathrm{Mn}$, and Fe were analyzed using an $\mathrm{LiF}$ diffractor. $\mathrm{Na}, \mathrm{Mg}, \mathrm{Al}$, and $\mathrm{Si}$ were counted on-peak for $30 \mathrm{~s}$ each. $\mathrm{Ca}, \mathrm{Ti}, \mathrm{Cr}, \mathrm{Mn}$, and Fe were counted on-peak for $20 \mathrm{~s}$ each. The 5 spectrometers were used to count multiple elements concurrently. Natural and synthetic mineral standards were used.

The same thin section was then analyzed using a Thermo Scientific MagnaRay parallel beam WDS spectrometer mounted on a field emission SEM. A $15 \mathrm{kV}$ accelerating voltage was used. The beam current was set to $25 \mathrm{nA}$ and measured at the beginning of each acquisition with an in-column Faraday cup. Mg, Al, and Si were analyzed using a TAP diffractor. Ca was analyzed using a PET diffractor. Ti, $\mathrm{Cr}, \mathrm{Mn}$, and $\mathrm{Fe}$ were analyzed using an LiF diffractor. On-peak count times for each element was determined by counting until a $1 \%$ error from counting statistics was achieved with a minimum count time of $5 \mathrm{~s}$ for all analyzed elements. $\mathrm{Mg}, \mathrm{Al}, \mathrm{Si}, \mathrm{Ca}, \mathrm{Ti}$, and $\mathrm{Fe}$ had maximum a count time of $20 \mathrm{~s}$. $\mathrm{Cr}$ and $\mathrm{Mn}$ had a maximum count time of $30 \mathrm{~s}$. Because there was only one WDS spectrometer on the SEM, all elements were measured in serial. Natural and synthetic mineral standards were used.

Pyroxene analyses acquired using the electron microprobe (red) and the SEM (blue) are plotted on a pyroxene quadrilateral in Fig. 1. Both instruments yield similar results for pigeonite, ferroaugite, and pyroxferroite compositions. Average pyroxene compositions obtained using each instrument are in Table 1.

Although WDS systems on SEMs currently do not fully replicate the analytical capabilities that exist for electron microprobes (e.g., interference corrections and time-dependent intensity corrections), they can yield similar quantitative results. A more practical approach for both electron microprobe and SEM- 
based X-ray microanalysis would be to rely on EDS standards-based analysis for many of the elements and analyze trace or minor elements by WDS.

References:

[1] SN North et al., LPS XLIV (2013) Abstract \#3013.

\begin{tabular}{|c|c|c|c|c|c|c|}
\hline \multirow[b]{2}{*}{ SEM } & \multicolumn{3}{|c|}{ SEM } & \multicolumn{3}{|c|}{ Electron microprobe } \\
\hline & Pig & FA & $\mathrm{PxF}$ & Pig & FA & $\mathrm{PxF}$ \\
\hline $\mathrm{n}$ & 12 & 20 & 2 & 130 & 81 & 2 \\
\hline $\mathrm{SiO}_{2}$ & 49.9 & 48.2 & 46.1 & 50.2 & 47.5 & 46.8 \\
\hline $\mathrm{TiO}_{2}$ & 0.56 & 0.85 & 0.92 & 0.44 & 0.81 & 0.63 \\
\hline $\mathrm{Al}_{2} \mathrm{O}_{3}$ & 1.01 & 1.03 & 0.77 & 1.38 & 1.25 & 0.71 \\
\hline $\mathrm{Cr}_{2} \mathrm{O}_{3}$ & 0.49 & 0.27 & 0.19 & 0.53 & 0.23 & 0.06 \\
\hline $\mathrm{FeO}$ & 25.5 & 33.0 & 41.1 & 24.3 & 31.5 & 39.3 \\
\hline $\mathrm{MnO}$ & 0.38 & 0.42 & 0.46 & 0.40 & 0.44 & 0.52 \\
\hline $\mathrm{MgO}$ & 14.5 & 6.76 & 2.27 & 14.4 & 6.56 & 3.88 \\
\hline $\mathrm{CaO}$ & 7.05 & 9.40 & 6.83 & 7.25 & 10.3 & 7.18 \\
\hline $\mathrm{Na}_{2} \mathrm{O}$ & - & - & - & 0.02 & 0.03 & 0.01 \\
\hline Total & 99.3 & 99.8 & 98.6 & 99.0 & 98.7 & 99.1 \\
\hline
\end{tabular}

"Pig" refers to pigeonite analyses. "FA" refers to ferroaugite analyses.

"PxF" refers to pyroxferroite analyses. Electron microprobe data is from [1].

Table 1. Average Pyroxene compositions from NWA 2727

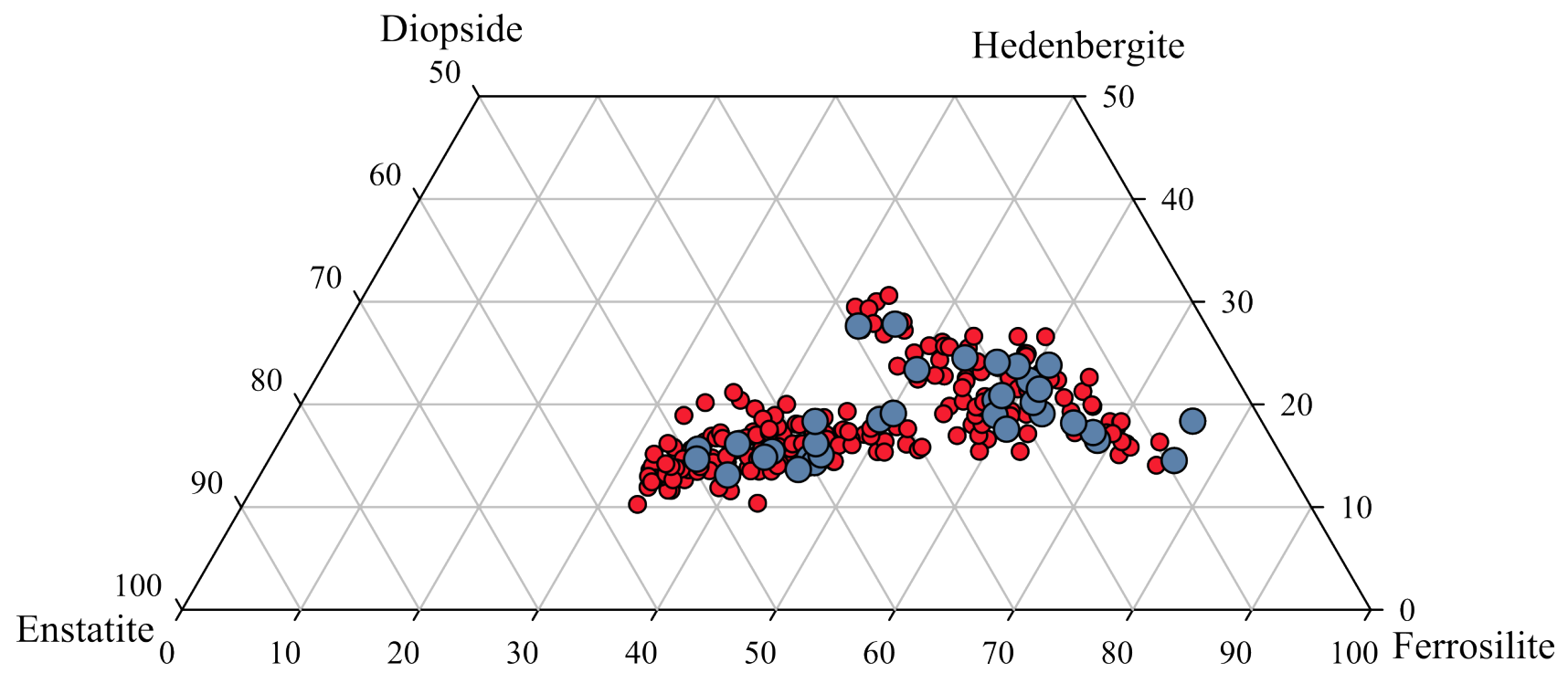

Figure 1. Pyroxene data analyzed using an electron microprobe (red) [1] and using a WDS system on an SEM (blue). 